\title{
Response to Fay's Comments: Apartheid and the Erosion or Preservation of Medicinal Plant Knowledge
}

\author{
Lisa Aston Philander
}

Published online: 25 March 2012

(C) Springer Science+Business Media, LLC 2012

The article 'Local Medicinal Plant Knowledge in South Africa Preserved by Apartheid' was not written to glorify or exonerate the institution of apartheid. Instead its rationale was to highlight the impacts of apartheid on contemporary South African urban environment and its effects on traditional medicinal plant knowledge. Typically urbanization results in disparate cultures' knowledge becoming eroded and homogenized over time. In most urban areas, multiple global, cultural and ethnic influences contribute to communal knowledge bases making it difficult to trace knowledge diffusion. Recent studies on urban medicinal plant knowledge suggest that group-specific knowledge amalgamates and morphs in the presence of other cultural knowledge (Napolitano and Mora Flores 2003; Pieroni and Vanderbroek 2007; Ceuterick et al. 2008). In South Africa, resettlement policies inadvertently contributed to a perpetuation of disparate spheres of knowledge, which may have been strengthened by the collective experience shared by segregated communities. One of Fay's critiques is that the causal conclusions of this article do not refer to a control group or baseline data. True, but anyone familiar with Cape Town's slums would recognize the pervasive and enduring effects of segregation and how it likely facilitated the preservation of some traditional knowledge through limiting free cross-cultural contacts. Fay contends that apartheid-era displacement and forced resettlement likely destroyed environmental knowledge. This does not contradict the above. In fact, the separation of cultural groups and races can be observed from the time of the inception of formal schooling and colonization (Davis 1972). The massive forced displacement and the collective experience of

L. Aston Philander $(\bowtie)$

University of Arizona,

Tucson, AZ, USA

e-mail: lisaphilander@gmail.com separation reinforces the likelihood that knowledge was preserved within groups.

While it is true that this research may be a record of the remnants of a rich and varied local knowledge of the Western Cape, several variables point to a continuity of knowledge among the Cape coloured community. The Cape coloured community was resettled near to their original homes within the same region and are therefore likely to encounter the same plant species that were originally used. In the Western Cape, urban townships to some extent are still surrounded by rural landscapes and rarely is public access restricted into the nearby extensive reserve network. Ethnobotanical research in the Western Cape depict that medicinal plant knowledge is centralized within rural and elderly coloured populations (Ferreira 1987; Ferreira et al. 1996). This lingering knowledge remains a feature of localized knowledge segregation that documents that medicinal plant knowledge is isolated within distinct groups.

Fay lists numerous questions that he argues are needed to arrive at the conclusions summarized in the article. To these I would like to address four in particular. First, the results and subsequent conclusions drawn here are specific to the Western Cape region where the majority of the population is not migrants from other provinces. Second, rural Transkei with a predominantly Xhosa speaking population surely reflects different outcomes of apartheid. Third, the issue of co-variation of ethnicity and urban residence posed in the critique is irrelevant if one assumes, as I did, that the populations had divergent knowledge bases to begin with because they originated in different biomes. Therefore, the majority of medicinal plants available to each group were different, and the study concerned plants that were common to both the Eastern and Western Capes. The research noted that Xhosa speakers were recent migrants who had greater knowledge of different medicinal plants species than did coloured or white students. The results 
of this research conclude that each group held distinctive plant knowledge indicating novel utilization by group of similar plants. Finally, the desegregated labor market has not led to a rapid transition away from medicinal plants; on the contrary, there has been a recent revitalization in the trade and use of medicinal plants among the Cape coloured community (Aston Philander 2011). Apartheid forced people to change their relationships to their environment resulting in the restriction of medicinal plant knowledge to cultural pockets, a situation that globally is quite exceptional.

\section{References}

Aston Philander, L. E. (2011). An ethnobotany of Western Cape Rasta bush medicine. Journal of Ethnopharmacology 138(2): 578-594.
Ceuterick, M., et al. (2008). Cross-Cultural adaptation in urban ethnobotany: The Columbian folk pharmacopeia in London. Journal of Ethnopharmacology 120: 342-359.

Davis, R. H. (1972). Bantu Education and the Education of Africans in South Africa. Ohio University Center for International Studies, Athens.

Ferreira, M. (1987). Medicinal use of indigenous plants by elderly coloureds: A sociological study of folk medicine. South African Journal of Sociology 18: 139-143.

Ferreira, M., Charlton, K., and Impey, L. (1996). Traditional medicinal use of indigenous plants by older coloureds in the Western Cape. In Normann, H., Snyman, I., and Cohen, M. (eds.), Indigenous Knowledge and its uses in Southern Africa. Human Sciences Research, Pretoria.

Napolitano, V., and Mora Flores, G. (2003). Complimentary Medicine: Cosmopolitan and popular knowledge and transcultural translationscases from urban Mexico. Theory, Culture, and Society 20(4): 7995.

Pieroni, A., and Vanderbroek, I. (2007). Traveling Cultures and Plants: The Ethnology and Ethnopharmacy of Human Migrations. Oxford Berghahn Books, New York. 